\title{
Barley development as affected by rate of change of photoperiod
}

\author{
G. C. KERNICH, G. A. SLAFER AND G. M. HALLORAN \\ Centre for Crop Improvement, Department of Agriculture, The University of Melbourne, Parkville, \\ Victoria 3052, Australia
}

(Revised MS received 7 June 1994)

\begin{abstract}
SUMMARY
The rate of leaf appearance of barley varies substantially with time of sowing. This variation has been related to both the length and the rate of change of photoperiod at the time of plant emergence. An outdoor pot experiment was conducted to test if rate of change of photoperiod directly affects phasic development and rate of leaf emergence of spring barley. Two photoperiod-sensitive cultivars (Bandulla and Galleon) were subjected to five photoperiod regimes: two constant photoperiods, of 14 and $15.5 \mathrm{~h}$, and three different rates of change of photoperiod of c. 2,9 and $13 \mathrm{~min} /$ day from seedling emergence to awn initiation.

Photoperiod treatments significantly affected the duration from seedling emergence to awn initiation in both cultivars. Rate of change of photoperiod did not affect the rate of development towards awn initiation independently of the absolute daylength it produced. Although Bandulla had a longer duration than Galleon at any photoperiod regime, the cultivars did not vary in their sensitivity to photoperiod. When this phase was divided into the leaf initiation (LI) and spikelet initiation (SI) phases, it was evident that the sensitivity to photoperiod was not constant, being in general higher during the SI than during the LI phase. However, the magnitude of the change in sensitivity was cultivar-dependent, indicating that sensitivity to photoperiod during the different phases could be under independent genetic control.

Final numbers of primordia (leaves together with maximum spikelet number) were negatively affected by increasing photoperiods, but once again, there was no evidence of any effect of the rate of change of photoperiod which was independent of the average photoperiod. Both cultivars showed similar sensitivities for final leaf number but maximum spikelet number was more sensitive to photoperiod in Galleon than in Bandulla.

Highly significant linear relationships between leaf number and thermal time were found for all combinations of cultivars and photoperiod regimes $\left(r^{2}>0.98\right)$. The rate of leaf appearance (RLA) was similar for both cultivars $\left(c .0 .0185\right.$ leaves $\left./{ }^{\circ} \mathrm{Cd}\right)$ and did not alter during plant development or in response to the change in photoperiod at awn initiation. The range in RLA was greater for Galleon $\left(0.0170-0.0205\right.$ leaves $\left./{ }^{\circ} \mathrm{Cd}\right)$ than for Bandulla $\left(0.0173-0.0186\right.$ leaves $\left./{ }^{\circ} \mathrm{Cd}\right)$. Neither of these cultivars exhibited a significant relationship between rate of leaf emergence and photoperiod or rate of change of photoperiod. The lack of significant relationships between RLA and length or rate of change of photoperiod is in contrast with previous reports using time of sowing as a main treatment.
\end{abstract}

\section{INTRODUCTION}

An understanding of the effects of environmental factors on plant development during the vegetative and early reproductive phases of barley can provide an insight into the determination of yield potential because the potential size of both the source and sink is formed during these phases. Photoperiod is one of the major factors influencing the rate and duration of plant development in winter cereals (Kirby \& Appleyard 1980; Kirby \& Ellis 1980; Roberts et al.
1988; Slafer \& Rawson 1994). The lengths of both the vegetative, or leaf initiation (LI), and spikelet initiation (SI) phases of cereals are reduced when plants are exposed to long photoperiods (Wall \& Cartwright 1974; Fairey et al. 1975; Allison \& Daynard 1976; Kirby \& Appleyard 1980; Rahman 1980; Cottrell et al. 1985; Craufurd \& Cartwright 1989; Kernich et al. 1993). Although longer photoperiods significantly increase the rate of primordia initiation in wheat and barley (Rahman \& Wilson 1977; Kirby \& Appleyard 1980; Rahman 1980; Cottrell et al. 1985), the 
reduction in lengths of developmental phases is most frequently greater, resulting in reductions in final numbers of both leaves and spikelets on the main shoot (Kirby \& Appleyard 1980; Rawson \& Richards 1993).

Another factor that could affect the rate of phasic development is the rate of change of photoperiod. The possible effect of this factor in barley has not been considered, but significant effects have been suggested on both timing of anthesis and final number of primordia for other crops such as maize (Bonhomme et al. 1991), wheat (Stapper \& Fischer 1990) and soyabean (Constable \& Rose 1988).

Leaf area index is the most important characteristic determining radiation interception (Gallagher \& Biscoe 1978), and rate of leaf appearance (RLA) is the most important developmental process determining the rate and extent of establishment of a plant canopy and hence of radiation interception. However, the effects of photoperiod on RLA are not as well understood as they are on the rate of phasic development.

It has been concluded from time-of-sowing experiments that the RLA is related to absolute photoperiod in barley (Jones \& Allen 1986; Wright \& Hughes 1987). However, several other environmental factors are changed by sowing at different times and experiments using photoperiod as a single treatment are required to test its possible effect on RLA. Cao \& Moss (1989), from a controlled environment experiment, reported a positive effect of increasing photoperiod on RLA in wheat and barley, but their photoperiod extensions were not performed with low intensity lights and thus the longer the photoperiod the higher the radiation, and it has been recently shown there can be a clear photoperiod $\times$ radiation interaction on developmental processes in wheat (Rawson 1993).

Other workers have related the effects of sowing date on RLA to the rate of change of photoperiod at seedling emergence (Baker et al. 1980; Kirby et al. 1985). Although this factor did not always predict the RLA of crops sown at different times (Hay \& Tunnicliffe Wilson 1982; Delecolle et al. 1985), it has been increasingly accepted during the last decade as a factor regulating RLA and used as a basis for modelling canopy development (Porter 1985).

No information has been published from a study in which the rate of change of photoperiod has been used as a treatment, so that the aim of this study was to examine whether this has any influence, independent of that of mean photoperiod on (i) duration of different phases of development, (ii) final leaf and spikelet number, and (iii) rate of leaf appearance in barley. To address this objective two cultivars of spring barley were subjected to a range of rates of change of photoperiod differing from 0 to $c .13$ $\min /$ day.

\section{MATERIALS AND METHODS}

\section{Treatments}

An outdoor pot experiment was carried out at the University of Melbourne Mt Derrimut Field Station $\left(37^{\circ} 47^{\prime} \mathrm{S}, 144^{\circ} 47^{\prime} \mathrm{E}\right)$. Treatments consisted of the factorial combination of two cultivars of spring barley and five photoperiod regimes. Both cultivars, Bandulla and Galleon, are sensitive to photoperiod (G. C. Kernich, unpublished).

The photoperiod regimes consisted of two constant photoperiods and three different rates of change of photoperiod (Fig. 1). The constant photoperiods of $14.0 \mathrm{~h}$ (medium constant photoperiod, MCP) and $15.5 \mathrm{~h}$ (high constant photoperiod, HCP) were established by extending the natural photoperiod with low intensity incandescent lights installed over the plants. They were switched on every day before sunset and switched off at predetermined times during the night to achieve the required photoperiod. The three increasing photoperiod regimes represented a wide range of rates of increase from that for Melbourne at the start of the study (c. $2.3 \mathrm{~min} /$ day, low rate of change of photoperiod, LRC), to c. $9 \mathrm{~min} /$ day (medium rate of change of photoperiod, MRC), or even outside the natural range (c. $13 \mathrm{~min} /$ day, high rate of change of photoperiod, HRC). They were established by extending the natural photoperiod every 3 days by 0,25 and $35 \mathrm{~min}$, respectively, using the same system as that described for the constant photoperiods. Plants were grown under these regimes from seedling emergence to the initiation of awn primordia (Kirby \& Appleyard 1987). After this stage all treatments were transferred to natural photo-

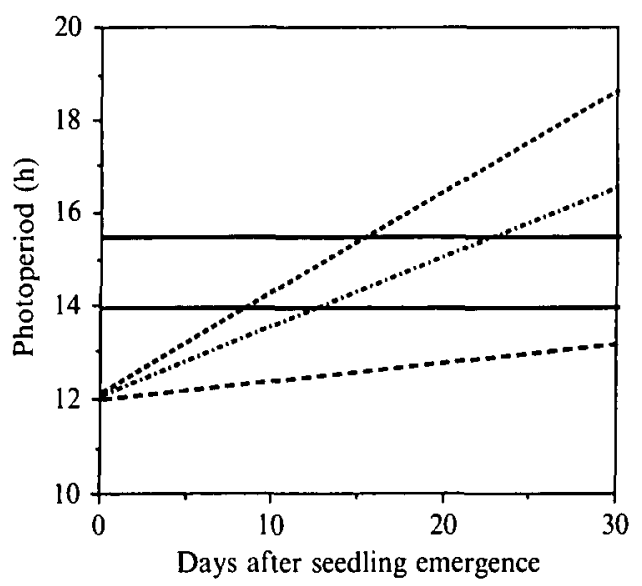

Fig. 1. Photoperiod for the five treatments over time. The two constant photoperiods (-) of 14 and $15.5 \mathrm{~h}$, the high rate of change (---) treatment (13 min/day, HRC), the medium rate (-....) of change treatment ( $9 \mathrm{~min} /$ day, MRC) and the natural daylength $(---)$, or low rate of change (c. $2 \mathrm{~min} /$ day, LRC) are shown. 
period. Photoperiod treatments were separated by light-proof plastic tarpaulins.

Six seeds of each cultivar were planted per pot $(17.5 \mathrm{~cm}$ diameter) on 24 August 1992. The potting mix was 3:2:1 by volume of Mt Derrimut red brown earth:peat: sand with adequate nutrients and water supplied. Treatments were arranged in a split-plot design using photoperiod regimes as main plots and cultivars as subplots. Within each photoperiod regime, cultivars were arranged in three blocks, each subplot containing five pots.

\section{Measurements}

The apical meristem of the main shoot of one plant per replicate per cultivar was dissected every $2-3$ days using a stereomicroscope to determine the developmental stage of the most advanced spikelet (Aspinall \& Paleg 1963) together with the number of emerged leaves (Haun 1973). At the awn initials stage the numbers of spikelets and leaves were determined on the main shoot. Plants for the dissections were progressively thinned down to two plants per pot at the awn initials stage. Leaf appearance was monitored every $2-3$ days from awn initials until the appearance of the flag leaf.

The length of the leaf initiation phase was calculated retrospectively using the final leaf number from sowing until the first spikelet was formed, and the corresponding mean photoperiod was calculated from seedling emergence to the formation of the first spikelet on the main shoot. The duration of the spikelet initiation phase was measured from the end of the leaf initiation phase until the awn initials stage of development on the ear of the main shoot.

Screen temperature was recorded hourly on a datalogger and thermal time between phases was calculated using a base temperature of $0^{\circ} \mathrm{C}$.

\section{Data analysis}

Linear regression analyses were applied to the relationships between leaf number and thermal time for each combination of cultivar and photoperiod regime. Final leaf number and spikelet number on the main tiller for the two cultivars across five photoperiod regimes were subjected to analysis of variance. The degree of association between variables was estimated by linear and curvilinear regression analyses. For examining the effect of photoperiod on development a bi-phasic model was fitted by eye (Major 1980; Roberts et al. 1988) whereby there was a negative response to photoperiod (that is, less time with increasing photoperiod) up to an optimum photoperiod at which there was no further response. The purpose of this was to establish if there was any effect of either absolute photoperiod, or of rate of change of photoperiod, on plant development independent of the average photoperiod. Because it was beyond the aims of this study, the amount of data collected was not large enough to verify quantitatively whether the bi-linear model was more or less appropriate than a curvilinear model in describing developmental changes.

\section{RESULTS}

\section{Phasic development}

Both cultivars showed a similar pattern of response to photoperiod, regardless of the fact that Galleon demonstrated a faster development rate under all photoperiods (Fig. 2). Both cultivars showed an optimum photoperiod of $c .14 \mathrm{~h}$ for the duration of the full period from seedling emergence to awn initiation. At photoperiods $<14 \mathrm{~h}$ there was an increase in duration from emergence to awn initiation for both cultivars (Fig. 2). There was no evidence of any effect of rate of change of photoperiod on duration from seedling emergence to awn initiation, independent of that produced by the mean photoperiod of the treatments. When the $\mathrm{LI}$ and SI phases were considered separately, different responses to photoperiod could be seen (Fig. $3 a-d$ ). The duration of the Ll phase for Bandulla sharply decreased with increasing photoperiods up to $14 \mathrm{~h}$ (Fig. $3 \mathrm{a}$ ) but Galleon showed only a slight decrease in duration of LI phase under the different photoperiod treatments (Fig. $3 b$ ).

The duration of the SI phase declined with increasing photoperiod for both cultivars (Fig. $3 c, d$ ) up to photoperiods of $c .15 \mathrm{~h}$. Under photoperiods

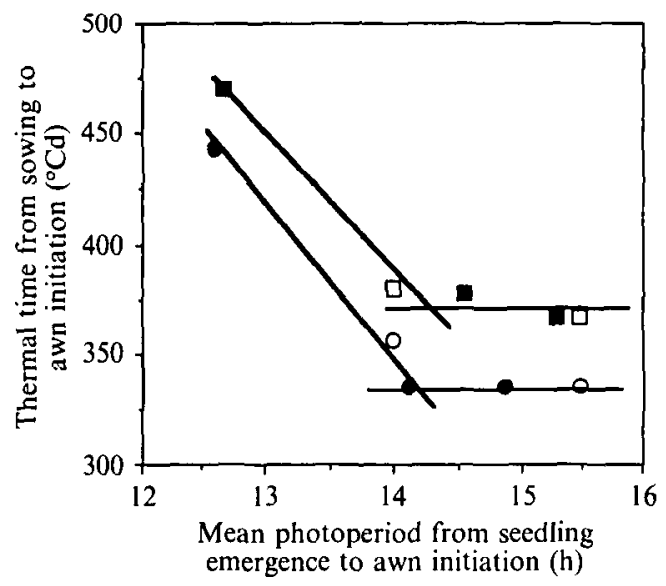

Fig. 2. The relationship of mean photoperiod (from seedling emergence to awn initiation) and thermal time (from sowing to awn initiation), for Bandulla $(\square, \square)$ and Galleon, $(O, O)$ subjected to constant photoperiod $(\square, O)$ and rate of change of photoperiod $(\square, 0)$ treatments. Lines representing the model described by Major (1980) and Roberts et al. (1988) were fitted by eye. 

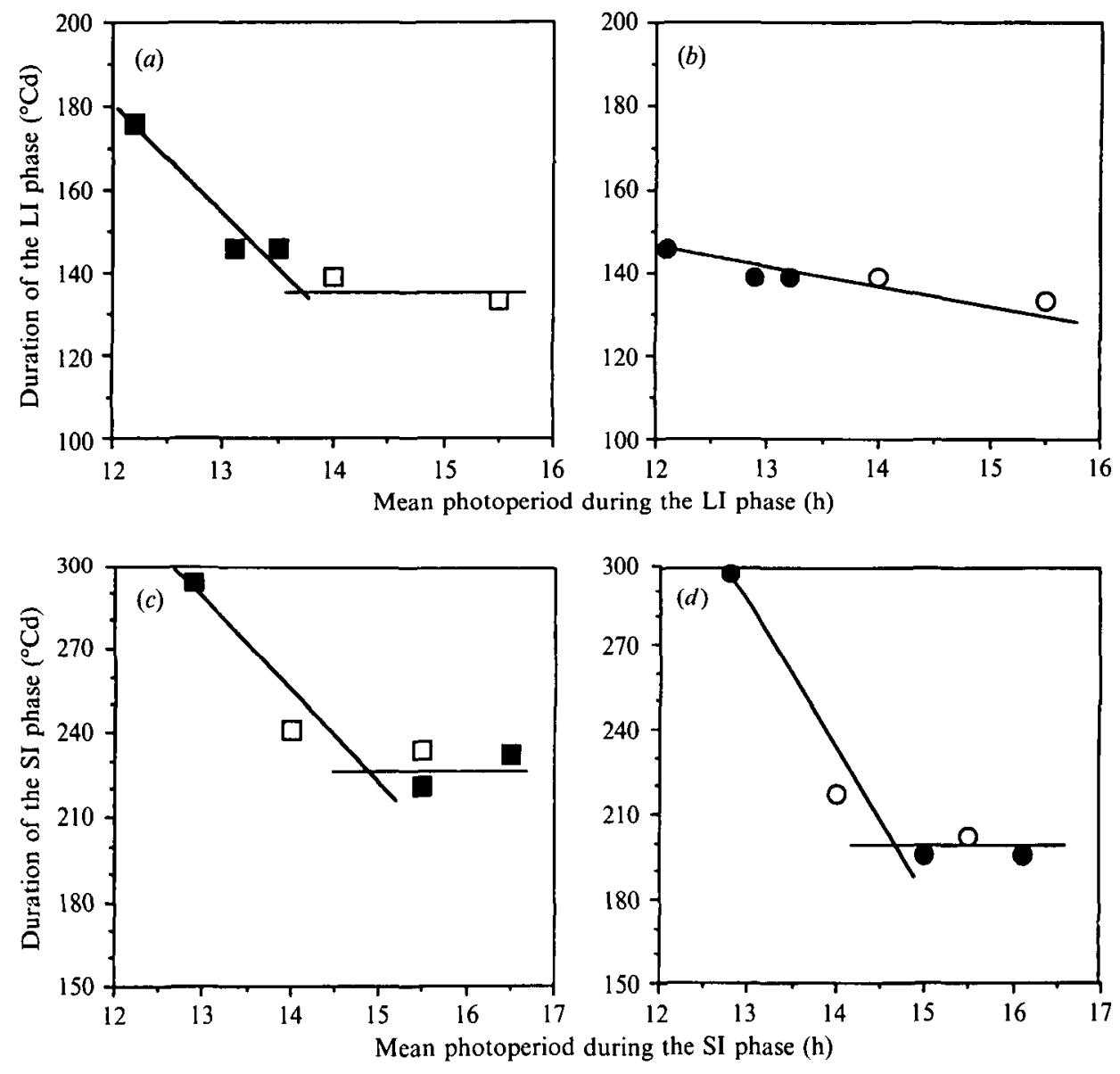

Fig. 3. The relationship between duration of the LI $(a, b)$ or SI $(c, d)$ phase and mean photoperiod for the LI or SI phase for five photoperiod treatments of Bandulla $(a, c)$ and Galleon $(b, d)$. Symbols as in Fig. 2. Lines were fitted by eye.

that minimized the duration of the SI phase, Galleon had a lower duration of this phase than Bandulla.

Contrary to the observed difference in the LI phase, the SI phase of Galleon was more sensitive to photoperiod than that of Bandulla. The relationship between photoperiod and phasic duration was different for the LI and SI phases, the latter being more sensitive than the former. This increase in sensitivity was slight in Bandulla (Fig. $3 a, c$ ) but pronounced in Galleon (Fig. $3 b, d$ ). There was no effect of rate of change of photoperiod on the duration of these phases which decreased with lengthening mean photoperiod (Fig. 3).

\section{Spikelet and leaf number}

The sum of the collar, leaf and spikelet primordia on the main tiller for the five photoperiod treatments was plotted against thermal time from sowing to awn initiation (Fig. 4a). Primordia number showed a curvilinear relationship with the period from seedling emergence to awn initiation. Data from treatments of different rate of change of photoperiod did not deviate from this relationship, indicating there was no effect of rate of change of photoperiod on primordia number. Final primordia number was also plotted against mean photoperiod from seedling emergence until awn initiation (Fig. $4 b$ ). With increasing photoperiod there was a decrease in primordia number for both cultivars, although the rate of decrease was faster in Galleon $(-5$ primordia $/ h$ ) than in Bandulla $(-3.5$ primordia/h).

However, both components of total primordia, leaf and spikelet numbers behaved differently (Fig. $5 a, b$ ). Final leaf number declined similarly in both cultivars as photoperiod increased during the LI phase and final leaf number and mean photoperiod during the LI phase were linearly related (Fig. $5 a$ ).

The maximum spikelet number (MSN) was evaluated at the awn initiation stage of development. 


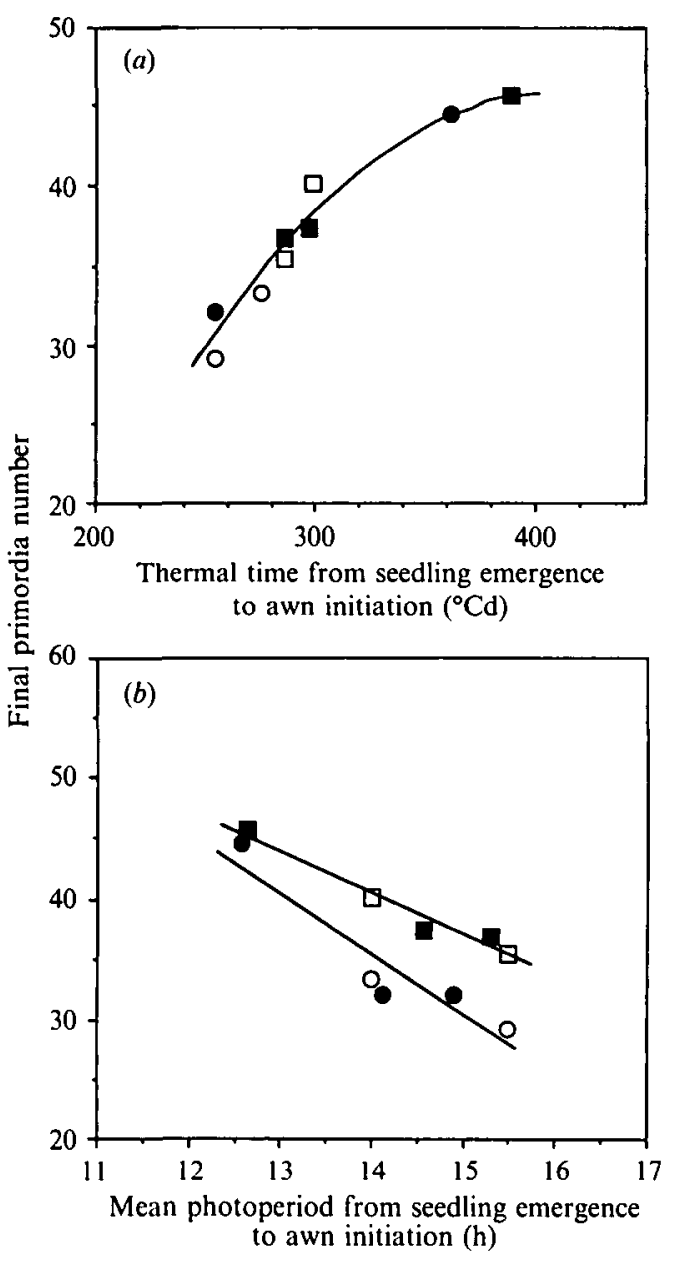

Fig. 4. The relationship between final primordia number (collar, leaf number + spikelet number) of the main shoot and either $(a)$ thermal time from seedling emergence to awn initiation or (b) mean photoperiod (from seedling emergence to awn initiation) for five photoperiod treatments of Bandulla and Galleon. Symbols as in Fig. 2. Regression equations for Bandulla and Galleon were $y=89 \cdot 0-3 \cdot 5 x(r=-0 \cdot 98)$, and $y=105.4-5 \cdot 0 \times(r=-0.93)$, respectively.

MSN declined with increasing photoperiod in both cultivars (Fig. $5 b$ ). There was however, a significant interaction $(P<0.001)$ between photoperiod and cultivar for MSN which indicated a slower decline in MSN with increasing photoperiod in Bandulla, compared with Galleon. There was no influence of rate of change of photoperiod on either final leaf number or MSN of Bandulla or Galleon (Fig. $5 a, b$ ).

The MSN values of Bandulla and Galleon were closely correlated with the amount of accumulated solar radiation to which the plants were exposed during the SI phase (Fig. $5 c$ ). Over the conditions of the experiment there was c. $33 \%$ reduction in
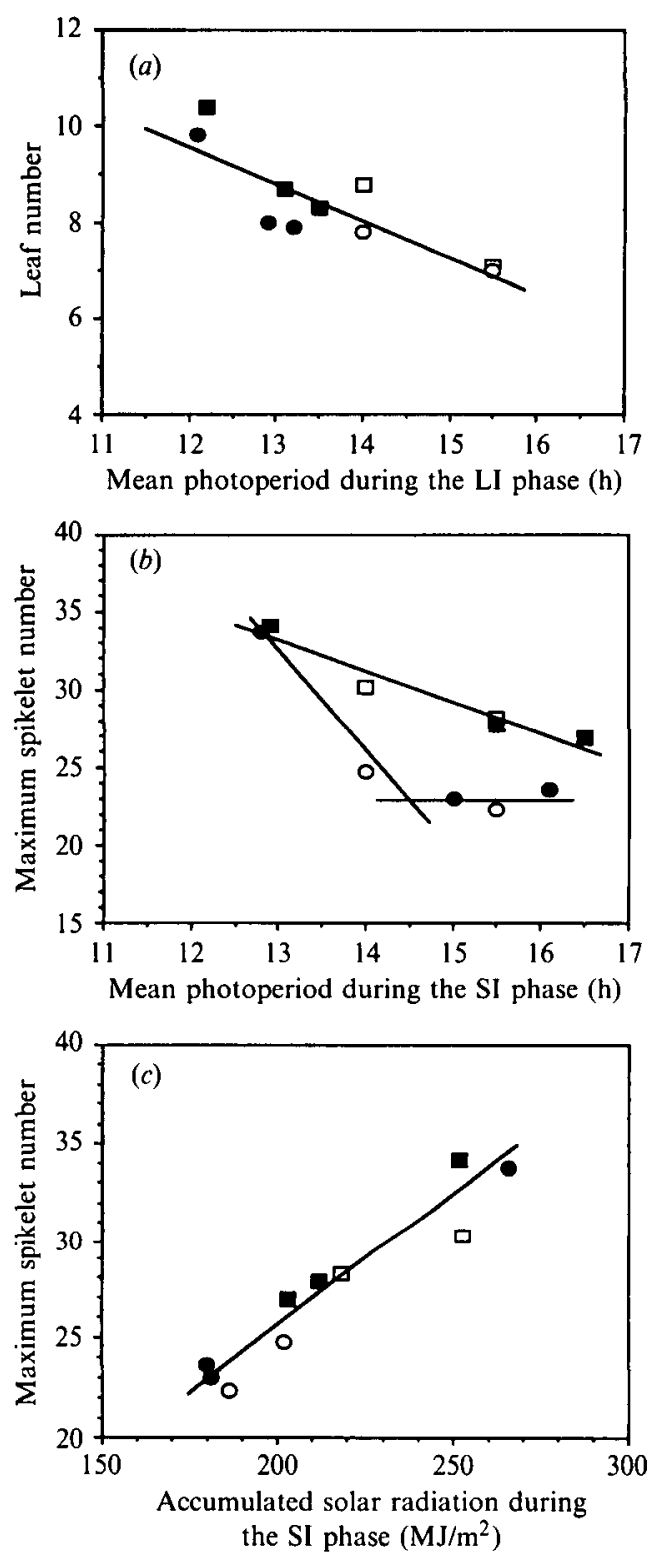

Fig. 5. The relationship between ( $a$ ) final leaf number and mean photoperiod for the LI phase $(b)$ maximum spikelet number and mean photoperiod (for the SI phase) and (c) maximum spikelet number and accumulated solar radiation during the SI phase $/ \mathrm{m}^{2}$ for five photoperiod treatments using two barley cultivars, Bandulla and Galleon. Symbols as in Fig. 2. Lines were fitted by regression $(a, c)$ or by eye (b). The regression equations were $(a) y=18.875-0.772 x$ $(r=-0.84)$ and $(c) y=0.128 x-0.123(r=0.96)$.

accumulated solar radiation during the SI phase and a $35 \%$ decrease in maximum spikelet number due to lengthened photoperiods. 

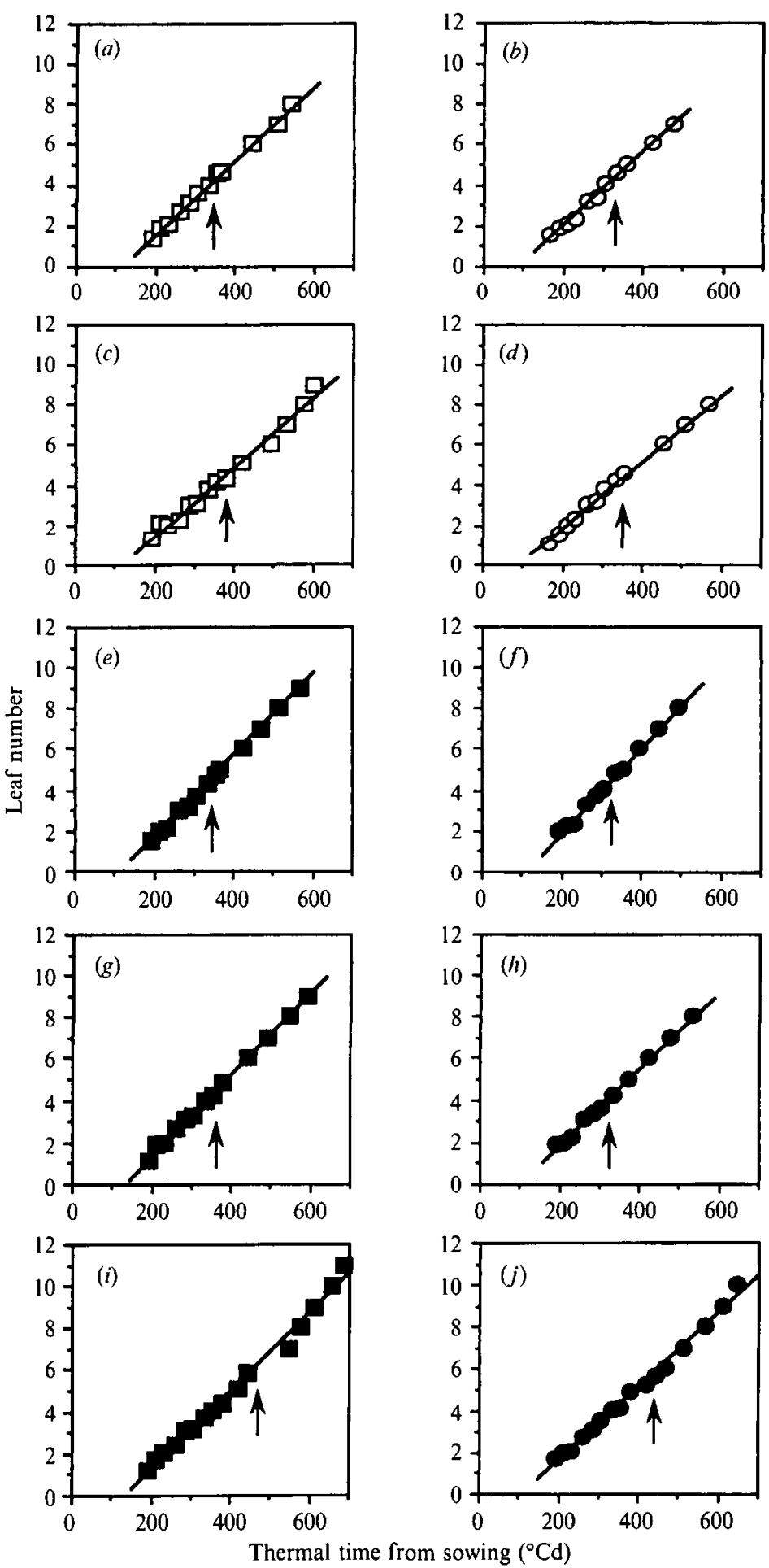

Fig. 6. The relationship between final leaf number on the main shoot and thermal time $\left({ }^{\circ} \mathrm{Cd}\right)$ for five photoperiod treatments of Bandulla $(a, c, e, g, i)$ and Galleon $(b, d, f, h, j)$. Treatments applied were constant photoperiod of $15.5 \mathrm{~h}(\mathrm{HCP} ; a, b), 14 \mathrm{~h}$ (MCP; $c, d$ ), high (HRC; $e, f$ ), medium (MRC; $g, h$ ), and low rate of change of photoperiod (LRC; $i, j$ ). Symbols as in Fig. 2. Lines were fitted by linear regression (see Table 1). Arrows indicate the time of awn initiation. 
Table 1. Parameters of the linear regression between number of leaves on the main culm and accumulated thermal time from seedling emergence in two barley cultivars, Bandulla and Galleon, subjected to different photoperiod regimes (Fig. 4). For each treatment the phyllochron and its standard error were calculated. For details of the photoperiod regimes see Fig. I. All the linear regressions had a highly significant $(P<0.001)$ F-ratio

\begin{tabular}{|c|c|c|c|c|c|c|}
\hline $\begin{array}{l}\text { Photoperiod } \\
\text { treatment }\end{array}$ & D.F. & $\begin{array}{c}\text { Slope } \\
\left.\text { (leaves } /{ }^{\circ} \mathrm{Cd}\right)\end{array}$ & S.E. & $r^{2}$ & $\begin{array}{c}\text { Phyllochron } \\
\left({ }^{\circ} \mathrm{Cd} / \text { leaf }\right)\end{array}$ & S.E. \\
\hline \multicolumn{7}{|c|}{ Bandulla } \\
\hline HCP & 10 & 0.0183 & 0.0003 & 0.99 & 54.54 & 0.92 \\
\hline MCP & 12 & 0.0173 & 0.0006 & 0.98 & $57 \cdot 10$ & $2 \cdot 00$ \\
\hline HRC & 11 & 0.0197 & 0.0002 & 0.99 & $50 \cdot 57$ & 0.62 \\
\hline MRC & 11 & 0.0191 & 0.0003 & 0.99 & $52 \cdot 33$ & 0.77 \\
\hline LRC & 14 & 0.0186 & 0.0005 & 0.99 & 53.23 & 1.41 \\
\hline \multicolumn{7}{|c|}{ Galleon } \\
\hline HCP & 9 & 0.0182 & 0.0005 & 0.99 & 54.72 & $1 \cdot 38$ \\
\hline MCP & 10 & 0.0170 & 0.0003 & 0.99 & $59 \cdot 18$ & $1 \cdot 26$ \\
\hline HRC & 9 & 0.0205 & 0.0005 & 0.99 & 48.67 & 1.09 \\
\hline MRC & 9 & 0.0183 & 0.0004 & 0.99 & $54 \cdot 35$ & 1.06 \\
\hline LRC & 14 & 0.0176 & 0.0004 & 0.99 & 56.25 & $1 \cdot 37$ \\
\hline
\end{tabular}

\section{Rate of leaf appearance}

The leaf number of each photoperiod treatment for both cultivars was plotted against thermal time (Fig. 6) and the linearity of the relationship allowed regression lines to be fitted. Although different photoperiod regimes ceased at awn initiation, simple linear regressions explained $>98 \%$ of the variation (Table 1), indicating that neither the transfer from artificial photoperiod treatments to natural photoperiod at awn initiation nor the progress in plant development had any impact on rate of leaf appearance.

Averaged across photoperiod regimes, both cultivars had similar rates of leaf appearance $(0.0186$ and 0.0183 leaves $/{ }^{\circ} \mathrm{Cd}$ for Bandulla and Galleon respectively). However, Galleon exhibited a wider range of RLA with photoperiod regimes than Bandulla (Table 1).

To test whether photoperiod or its rate of change was responsible for this variation in RLA, regressions of RLA with each factor were calculated (Fig. 7). When the RLA was plotted against mean photoperiod (Fig. 7a) there was no effect of rate of change of photoperiod, although RLA under constant photoperiods tended to be lower than under increasing photoperiods for both cultivars. In addition RLA showed little change over the range of photoperiods used for both cultivars. The relationship between RLA and rate of change of photoperiod was not as clear (Fig. $7 b$ ). When the data for both cultivars were pooled, a significant association $(r=0.79, P<0.01$, $n=10$ ) was found. Although this response was significant, the magnitude of the RLA was small and the effect of rate of change of photoperiod on RLA appeared to be much less than that of previous experiments using time-of-sowing treatments (Fig.
$7 b$ ). However neither cultivar showed a significant relationship when analysed separately (Fig. $7 b$ ).

\section{DISCUSSION}

The observed decrease in the duration of the vegetative and early reproductive phases of barley with increasing mean photoperiod is consistent with published data (Rahman \& Wilson 1977; Kirby \& Appleyard 1980, Kernich et al. 1993). When the whole period from sowing to awn initiation was considered, bilinear, or curvilinear, responses of duration to mean photoperiod were found. Although at each mean photoperiod Galleon had a lower duration than Bandulla, their sensitivity (or response) to photoperiod was similar. For both cultivars, the optimum photoperiod at which there was no further response to photoperiod was $c$. 14-15 h. However, when the LI and SI phases were considered separately, different responses to photoperiod, both between cultivars and between phases, could be seen. The SI phase was more sensitive than the LI phase, the difference being high in Galleon and only slight in Bandulla. This increase in sensitivity from the vegetative to the early reproductive phases is strongly supported in the present study by the data obtained at a $13 \mathrm{~h}$ photoperiod, and this finding closely agrees with observations reported by other authors (Allison \& Daynard 1976; Rahman \& Wilson 1977; Rahman 1980). This lack of association between responses to photoperiod during different phases indicates that the sensitivities of these phases are largely independent (Slafer \& Rawson 1994). Consequently we suggest that they could also be under separate genetic control and that they could possibly be manipulated independently. In contrast to the effects of absolute 


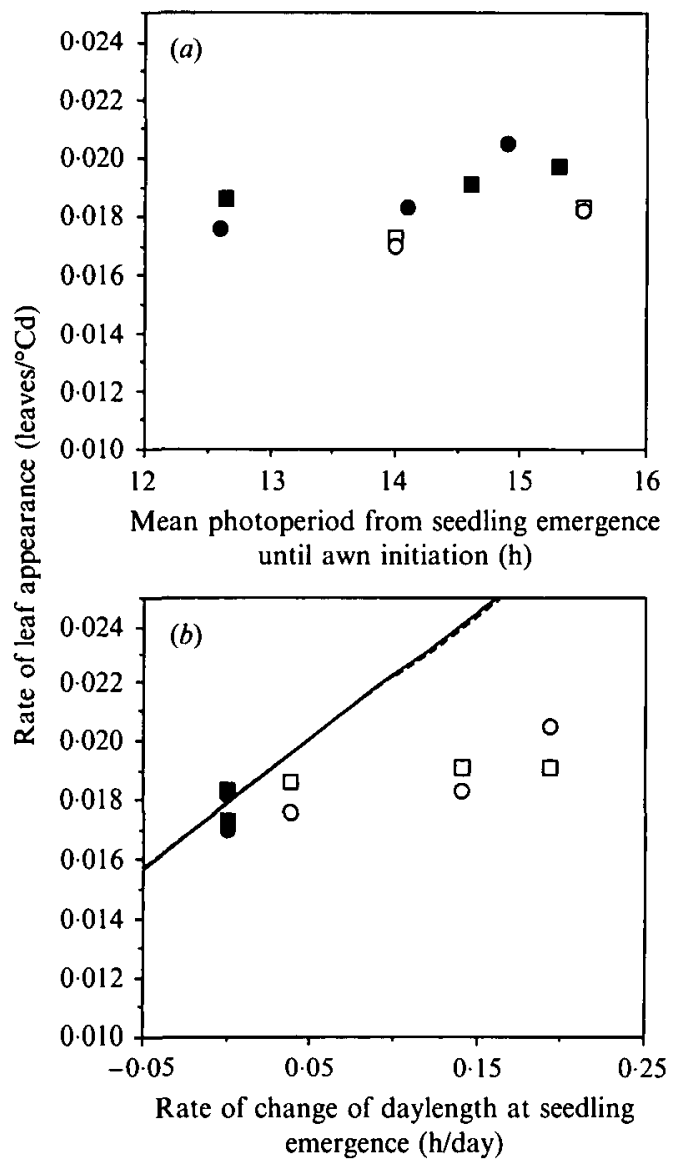

Fig. 7. The relationship between rate of leaf appearance and either (a) mean photoperiod from seedling emergence to awn initiation or $(b)$ rate of change of daylength at emergence for five photoperiod treatments of Bandulla and Galleon. Symbols as in Fig. 2. Lines in Fig. $7 b$ represent the slopes reported by Ellis \& Russell (1984) (-) and Kirby et al. (1982) (--) using an intercept of 0.018 leaves $/{ }^{\circ} \mathrm{Cd}$.

photoperiod, the rate of change of photoperiod did not affect developmental rates in the two barley cultivars.

While there are no data available from experiments objectively imposing different rates of change of photoperiod as treatments, our results contrast with the proposal raised from time-of-sowing experiments in which it has been suggested that rate of change of photoperiod would affect the rate of development towards anthesis (Constable \& Rose 1988; Stapper \& Fischer 1990; Bonhomme et al. 1991).

The effect of increasing photoperiod on lowering leaf number and spikelet number on the main tiller of barley plants has been reported previously (Kirby \& Appleyard 1980). Little, however, has been reported on the effect of rate of change of photoperiod per se on leaf and spikelet number. While there was no effect of rate of change of photoperiod on final primordia number, there was a strong response to mean photoperiod, the magnitude differing between cultivars. The lack of linearity between final primordia number and thermal time from seedling emergence to awn initiation indicates that under the least inductive photoperiods the rate of primordia initiation would have been reduced. Rawson \& Richards (1993) also found that extended delays (due to short photoperiod under relatively high temperature) in phasic development did not result in a parallel increase in primordia numbers, since primordia initiation on the apex slowed. Both spikelet and leaf numbers of Bandulla responded linearly to photoperiod whereas those of Galleon exhibited a curvilinear response.

In the present study, leaf numbers were always linearly related to thermal time, indicating that (i) the progress in plant development towards heading or (ii) changes in environmental conditions during reproductive phases did not significantly affect RLA. This strengthens the argument that environmental conditions during the earliest stages of development govern the time course of leaf emergence per degree day until the appearance of the flag leaf, as reported by other authors (Baker et al. 1980; Kirby et al. 1982; Hay \& Kirby 1991).

It has been shown from time-of-sowing trials that RLA varies with changes in sowing date and it has been reported that the rate of change of photoperiod at the time of seedling emergence may be the environmental factor responsible for this variation, since RLA in barley has been found to be positively and linearly correlated with the rate of change of photoperiod (Kirby et al. 1982, 1985; Ellis \& Russell 1984). The hypothesis was first proposed by Baker et al. (1980) for wheat and has been subsequently reported for wheat, barley and wild oats (Hay \& Abbas Al-Ani 1983; Delecolle et al. 1985; Kirby et al. 1985; Kirby \& Perry 1987; Cousens et al. 1992).

In the present study, in which rate of change of photoperiod was used as a primary treatment, no influence of rate of change of photoperiod at plant emergence, or mean daylength, on RLA was evident. The fact that we did not explore a full range of rates of change of photoperiod leaves room for some specific effects of negative rates (such as those proposed by Stapper \& Fischer (1990)). However, time-of-sowing studies reporting a significant relationship between RLA and rate of change of photoperiod show a linear association including both negative and positive values (e.g. Baker et al. 1980). In addition, unpublished results from controlled experiments conducted in the UK (Kirby et al. 1983) and USA (J. T. Ritchie, personal communication) in which positive and negative rates of change of photoperiod were direct treatments, are in agreement with the lack of effects on RLA found in the present 
study. The conclusions of Hay \& Kirby (1991) that time of sowing is the most important factor affecting RLA is obviously valid but other factors must be responsible for this.

Some alternative hypotheses have been suggested. Masle et al. (1989) and Cousens et al. (1992) found RLA was correlated to photothermal time in wheat. Porter \& Delecolle (1988) proposed that changes in RLA may be due to shifts in base temperature. Finally Rawson (1993) proposed that the source-sink ratios (reflected by the photothermal quotient) could be the reason for slower development of wheat plants sown in autumn. It is concluded that rate of change of photoperiod did not have any effect on (i) phasic development, or (ii) primordia numbers, independently of the effect produced by the mean photoperiod corresponding to that rate of change of photoperiod treatment. Increases in absolute photoperiod reduced the length of the SI phase more strongly than that of the $\mathrm{LI}$ phase, particularly in Galleon, suggesting independence of the response between developmental phases.

Rate of leaf appearance was not significantly affected by either absolute photoperiod or its rate of change in either of the two cultivars. Therefore, it is likely that differences observed in RLA under different sowing dates must be due to factor(s) other than variation in photoperiod, such as changes in base temperature or in source-sink ratios.

We thank H. M. Rawson and R. A. Richards (CSIRO, Canberra) for comments on the manuscript. G. C. Kernich is grateful to the Grains Research and Development Corporation for support. G. A. Slafer is on leave from the Department of Plant Production, Faculty of Agronomy, University of Buenos Aires and gratefully acknowledges the support given by CONICET (Consejo Nacional de Investigaciones Cientificas y Tecnicas, Argentina) and The University of Melbourne.

\section{REFERENCES}

Allison, J.C. S. \& Daynard, T. B. (1976). Effect of photoperiod on development and number of spikelets of a temperate and some low-latitude wheats. Annals of Applied Biology 83, 93-102.

Aspinall, D. \& PaleG, L. G. (1963). Effects of daylength and light intensity on growth of barley. 1. Growth and development of apex with a fluorescent light source. Botanical Gazette 124, 429-437.

Baker, C. K., Gallagher, J. N. \& Monteith, J. L. (1980). Daylength change and leaf appearance in winter wheat. Plant, Cell and Environment 3, 285-287.

Bonhomme, R., DerieuX, M., Kiniry, J. R., Edmeades, G. O. \& OzIER-LAFONTAINE, H. (1991). Maize leaf number sensitivity in relation to photoperiod in multilocation field trials. Agronomy Journal 83, 153-157.

CAO, W. \& Moss, D. N. (1989). Daylength effect on leaf emergence and phyllochron in wheat and barley. Crop Science 29, 1021-1025.

Constable, G. A. \& Rose, I. A. (1988). Variability of soybean phenology response to temperature, daylength and rate of change in daylength. Field Crops Research 18, 57-69.

Cousens, R. D., Johnson, M. P., Weaver, S. E., Martin, T. D. \& BlaiR, A. M. (1992). Comparative rates of emergence and leaf appearance in wild oats (Avena fatua), winter barley (Hordeum sativum) and winter wheat (Triticum aestivum). Journal of Agricultural Science, Cambridge 118, 149-156.

Cottrell, J. E., Easton, R. H., Dale, J. E., Wadsworth, A. C., Adam, J. S., ChILd, R. D. \& HoAd, G. V. (1985). A comparison of spike and spikelet survival in mainstem and tillers of barley. Annals of Applied Biology 106, 365-377.

Craufurd, P. Q. \& Cartwright, P. M. (1989). Effect of photoperiod and chlormequat on apical development and growth in a spring wheat (Triticum aestivum) cultivar. Annals of Botany 63, 515-525.
Delecolle, R., Couvreur, F., Pluchard, P. \& VarletGrancher, C. (1985). About the leaf-daylength model under French conditions. In Wheat Growth and Modelling (Eds W. Day \& R. K. Atkin), pp. 25-31. New York: Plenum Press.

Ellis, R. P. \& Russell, G. (1984). Plant development and grain yield in spring and winter barley. Journal of Agricultural Science, Cambridge 102, 85-95.

Fairey, D. T., Hunt, L. A. \& Stoskopf, N. C. (1975). Daylength influence on reproductive development and tillering in 'Fergus' barley. Canadian Journal of Botany 53, 2770-2775.

Gallagher, J. N. \& BisCOE, P. V. (1978). Radiation absorption, growth and yield of cereals. Journal of Agricultural Science, Cambridge 91, 47-60.

HaUN, J. R. (1973). Visual quantification of wheat development. Agronomy Journal 65, 116-119.

Hay, R. K. M. \& AbBas Al-ANi, M. K. (1983). The physiology of forage rye (Secale cereale). Journal of Agricultural Science, Cambridge 101, 63-70.

Hay, R. K. M. \& KIRBY, E. J. M. (1991). Convergence and synchrony - a review of the coordination of development in wheat. Australian Journal of Agricultural Research 42, $661-700$.

Hay, R. K. M. \& Tunnicliffe Wilson, G. (1982). Leaf appearance and extension in field-grown winter wheat plants: the importance of soil temperature during vegetative growth. Journal of Agricultural Science, Cambridge 99, 403-410.

Jones, J. L. \& Allen, E. J. (1986). Development in barley (Hordeum sativum). Journal of Agricultural Science, Cambridge 107, 187-213.

Kernich, G. C., Halloran, G. M. \& Flood, R. G. (1993). The effect of photoperiod on reproductive development and culm elongation rate in barley. In Proceedings of the 10th Australian Plant Breeding Conference. Vol. 2 (Ed. B. C. Imrie), pp. 101-102. University of Queensland Printing Service. 
KIRBY, E. J. M. \& APpleyard, M. (1980). Effects of photoperiod on the relation between development and yield per plant of a range of spring barley varieties. Zeitschrift für Pfanzenzüchtung 85, 226-239.

Kirby, E. J. M. \& Appleyard, M. (1987). Cereal Development Guide. Stoneleigh, UK: NAC Cereal Unit.

KiRBY, E. J. M. \& Ellis, R. P. (1980). A comparison of spring barley grown in England and in Scotland. 1. Shoot apex development. Journal of Agricultural Science, Cambridge 95, 101-110.

Kirby, E. J. M. \& Perry, M. W. (1987). Leaf emergence rates of wheat in a Mediterranean environment. Australian Journal of Agricultural Research 38, 455-464.

Kirgy, E. J. M., Appleyard, M. \& Fellowes, G. (1982). Effect of sowing date on the temperature response of leaf emergence and leaf size in barley. Plant, Cell and Environment 5, 477-484.

Kirby, E. J. M., Appleyard, M. \& Fellowes, G. (1983). Rate of change of daylength and leaf emergence. 1982 Annual Report Plant Breeding Station, Cambridge, p. 115.

KIRBY, E. J. M., Appleyard, M. \& Fellowes, G. (1985). Effect of sowing date and variety on main shoot leaf emergence and number of leaves of barley and wheat. Agronomie 5, 117-126.

MaJoR, D. J. (1980). Photoperiod response characteristics controlling flowering of nine crop species. Canadian Journal of Plant Science 60, 777-784.

Masle, J., Doussinault, G., Farquhar, G. D. \& Sun, B. (1989). Foliar stage in wheat correlates better to photothermal time than to thermal time. Plant, Cell and Environment 12, 235-247.

PORTER, J. R. (1985). Approaches to modelling canopy development in wheat. In Wheat Growth and Modelling (Eds W. Day \& R. K. Atkin), pp. 69-81. New York: Plenum Press.

Porter, J. R. \& Delecolle, R. (1988). Interaction of temperature with other environmental factors in controlling the development of plants. In Plants and Temperature (Eds S. P. Long \& F. I. Woodward), pp. 133-156. Cambridge: Company of Biologists.
RaHMAN, M. S. (1980). Effect of photoperiod and vernalization on the rate of development and spikelet number per ear in 30 varieties of wheat. Journal of the Australian Institute of Agricultural Science 46, 68-70.

Rahman, M. S. \& Wilson, J. H. (1977). Determination of spikelet number in wheat. l. Effect of varying photoperiod on ear development. Australian Journal of Agricultural Research 28, 565-574.

Rawson, H. M. (1993). Radiation effects on rate of development in wheat grown under different photoperiods and high and low temperatures. Australian Journal of Plant Physiology 20, 719-727.

Rawson, H. M. \& Richards, R. A. (1993). Effects of high temperature and photoperiod on floral development in wheat isolines differing in vernalisation and photoperiod genes. Field Crops Research 32, 181-192.

Roberts, E. H., Summerfield, R. J., CoOper, J. P. \& Ellis, R. H. (1988). Environmental control of flowering in barley (Hordeum vulgare L.). I. Photoperiod limits to long-day responses, photoperiod-insensitive phases and effects of low-temperature and short-day vernalization. Annals of Botany 62, 127-144.

Slafer, G. A. \& Rawson, H. M. (1994). Sensitivity of wheat phasic development to major environmental factors: a reexamination of some assumptions made by physiologists and modellers. Australian Journal of Plant Physiology 21, 393-426.

StAPPER, M. \& Fischer, R. A. (1990). Genotype, sowing date and plant spacing influence on high-yielding irrigated wheat in southern New South Wales. I. Phasic development, canopy growth and spike production. Australian Journal of Agricultural Research 41, 997-1019.

Wall, P. C. \& CARTWRight, P. M. (1974). Effects of photoperiod, temperature and vernalization on the phenology and spikelet numbers of spring wheats. Annals of Applied Biology 76, 299-309.

WRIGHT, D. \& HuGHES, LL. G. (1987). Relationships between time, temperature, daylength and development in spring barley. Journal of Agricultural Science, Cambridge 109, 365-373. 